\title{
MATRIZES DE TRANSIÇÃO DE RISCO DE CRÉDITO
}

Patrick Alves

João Alberto De Negri²

\section{SINOPSE}

O monitoramento da evolução do risco de crédito e da qualidade dos credores pode ser determinante na redução dos spreads bancários e na melhoria do acesso a crédito no Brasil. As matrizes de transição de risco de crédito possuem este propósito, pois fornecem projeçóes de probabilidades de mudanças de status de rating de crédito para contratos em andamento. Este trabalho apresenta as matrizes de transiçóes de risco de crédito para firmas brasileiras, comparando as linhas de créditos operados com recursos livres e direcionados.

Palavras-chave: risco de crédito; crédito livre; crédito direcionado; rating de crédito.

DOI: http://dx.doi.org/10.38116/radar63art4

\section{INTRODUÇÃO}

O monitoramento da evolução do risco de crédito e da qualidade dos credores pode ser determinante na redução dos spreads bancários e na melhoria do acesso a crédito no Brasil. As matrizes de transição de risco de crédito possuem este propósito, pois fornecem projeçóes de probabilidades de mudanças de status de rating de crédito para contratos em andamento (Koopman, Lucas e Monteiro, 2008). Estas matrizes também servem para avaliar os ajustes necessários na perda esperada das instituiçóes financeiras, um dos requisitos do Acordo de Basileia, e permitem projetar a composição dos níveis de risco de crédito em diferentes horizontes de tempo.

\section{DEBATE/DISCUSSÃO}

Apresentamos as matrizes de transiçóes de risco de crédito para firmas brasileiras, comparando as linhas de créditos operados com recursos livres e direcionados. As operaçôes de crédito direcionado são realizadas principalmente por instituições como Banco Nacional de Desenvolvimento Econômico e Social (BNDES), Caixa Econômica Federal, Banco do Brasil e bancos de desenvolvimento (BDs). Já as linhas de crédito com recursos livres são operadas em grande parte por instituições financeiras privadas. Os resultados mostram que nas primeiras há maior probabilidade de transiçôes em relaçáo às classificaçóes originais, ocorrendo melhoras de ratings comparativamente aos recursos livres. Por sua vez, as últimas são alocadas para operaçóes com melhores classificaçóes iniciais em comparação aos recursos direcionados, sofrendo menos transiçôes em relação à atribuição de rating inicial no decorrer do seu ciclo de vida. Os resultados indicam ainda que os modelos de atribuiçáo de risco utilizados

1. Pesquisador do Programa de Pesquisa para o Desenvolvimento Nacional (PNPD) na Diretoria de Estudos e Políticas Setoriais de Inovação e Infraestrutura (Diset) do Ipea.

2. Técnico de planejamento e pesquisa e coordenador de estudos em financiamento e investimento na Diset/lpea. 
em linhas de crédito direcionado parecem ser mais frágeis que aqueles utilizados pelas instituições privadas. Em contrapartida, as transições em direção à melhoria de rating podem indicar que, de alguma forma, o acesso ao crédito contribuiu para a recuperação financeira das empresas.

A deterioração da qualidade dos credores, associada à ausência ou omissão na monitoraçáo da qualidade do crédito, potencializou efeitos indesejados de contágio e depreciação na confiança de investidores e consumidores (Hull, 2009). Esta investigação é motivada também pelas consequências da Resolução no 2.682/1999 do Banco Central do Brasil (BCB) diante do atual cenário de expansão do crédito. A resolução estabelece os níveis mínimos de provisão requeridos pelas instituições financeiras (tabela 1). Alteraçôes do nível de risco devido aos atrasos recorrentes no pagamento das parcelas implicam o aumento dos custos de provisão, impactando a oferta geral de crédito das instituiçóes, uma vez que os recursos adicionais provisionados não podem ser utilizados em novas operaçóes.

TABELA 1

Provisões de crédito conforme os níveis de risco

\begin{tabular}{|c|c|c|c|c|c|c|c|c|c|}
\hline Ratings & AA & A & B & C & D & $\mathrm{E}$ & $\mathrm{F}$ & G & $\mathrm{H}$ \\
\hline Dias de atraso & - & - & 15 a 30 & 31 a 60 & 61 a 90 & 91 a 120 & 121 a 150 & 151 a 180 & $>180$ \\
\hline Livre & 19,6 & 48,9 & 16,7 & 11,1 & 2,6 & 0,5 & 0,2 & 0,1 & 0,4 \\
\hline Direcionado & 17,9 & 37,7 & 17,3 & 20,0 & 4,0 & 1,0 & 0,5 & 0,2 & 1,3 \\
\hline
\end{tabular}

Fonte: Yanaka e Holland (2010) e Sistema de Informações de Crédito do Banco Central do Brasil (SCR).

Elaboração dos autores.

\section{METODOLOGIA E RESULTADOS}

As matrizes de transição de risco de crédito foram construídas por meio de frequências históricas a partir dos dados do SCR, comparando-se o rating de crédito inicial e final. Seguimos a orientação de Jones (2005), que aconselha a construção de matrizes de transição para longos períodos de tempo, de forma a evitar a contaminação por efeitos de ciclos econômicos. As matrizes apresentadas foram construídas para o período de 2004 a 2017, para 378.651 empresas distintas, dos setores de indústria, comércio, serviços e construção civil. Juntas essas empresas possuíam 910 milhóes de operaçóes de crédito ativas mensalmente no período.

De acordo com o BCB, metade do crédito no país é crédito direcionado ${ }^{3}$ ( $\mathrm{R} \$ 1,54$ trilhão em 2016). A tabela 1 mostra que 55,6\% dos recursos direcionados são alocados para operaçóes com ratings A e AA, enquanto 7\% são alocados para operaçôes com ratings abaixo de D. Nos recursos livres, 68,5\% são alocados para operaçôes com classificaçôes A e AA, enquanto 3,8\% são alocados para ratings abaixo de D. Devido à melhor alocação inicial, as operaçóes de crédito livre sofrem menos transiçóes na direção de melhoria de ratings (upgrade). Entretanto, essas operaçóes também sofrem menos transiçóes de piora de ratings (downgrade).

A matriz de transição para crédito livre mostra que 80,9\% das operações AA e 79,9\% das operaçóes A mantêm a sua classificação original de crédito. As maiores probabilidades de piora de classificação ocorrem nas classificaçôes menores ou iguais à D. Estas são consideradas operaçóes especulativas (Wang et al., 2017), ou seja, nas operaçóes de crédito livre, as pioras ocorrem naquelas já degeneradas. Para as operaçóes classificadas com rating $\mathrm{G}$, somente 15,3\% apresentaram recuperação de rating, 35,5\% mantiveram sua classificação original e 49,3\% pioraram de classificação de rating (tabela 2). Os resultados mostram maior conservadorismo das operaçóes com recursos

3. Ver definição de crédito livre e direcionado em: <https://www.bcb.gov.br/content/estatisticas/docs_estatisticasmonetariascredito/glossariocredito.pdf>. 
de crédito livre. As operaçóes especulativas, quando ocorrem, possuem alta probabilidade de permanência em um quadro de inadimplência, com degeneração da classificação de rating.

\section{TABELA 2}

Matriz de transição de risco de crédito livre

(Em \%)

\begin{tabular}{lrrrrrrrrr}
\hline \multirow{2}{*}{ Rating inicial } & \multicolumn{10}{c}{ Rating de crédito final } \\
\cline { 2 - 11 } & AA & A & B & C & D & E & F & G & H \\
\hline AA & 80,9 & 8,1 & 5,1 & 3,2 & 0,8 & 0,4 & 0,2 & 0,2 & 1,2 \\
A & 5,1 & 79,9 & 6,5 & 4,3 & 1,5 & 0,5 & 0,3 & 0,3 & 1,6 \\
B & 5,9 & 13,2 & 60,1 & 11,9 & 3,8 & 1,1 & 0,5 & 0,6 & 3,0 \\
C & 1,2 & 6,3 & 8,5 & 67,9 & 6,8 & 2,0 & 1,1 & 1,0 & 5,2 \\
D & 0,8 & 7,4 & 4,9 & 13,3 & 48,7 & 5,9 & 2,9 & 2,6 & 13,5 \\
E & 0,5 & 5,1 & 2,5 & 5,6 & 8,6 & 43,3 & 6,9 & 4,1 & 23,3 \\
F & 1,5 & 4,7 & 2,9 & 4,3 & 5,6 & 4,4 & 43,7 & 5,8 & 27,3 \\
G & 0,4 & 2,6 & 1,2 & 2,5 & 3,8 & 2,2 & 2,6 & 35,5 & 49,3 \\
H & 0,3 & 2,8 & 1,2 & 1,8 & 1,9 & 0,9 & 2,8 & 0,7 & 87,6 \\
\hline
\end{tabular}

Fonte: SCR.

Elaboração dos autores.

Obs.: As linhas somam 100\%, e as probabilidades de piora nos ratings são obtidas pela diferença entre a diagonal e as linhas da matriz triangular superior.

A matriz de probabilidades de transição para linhas de crédito direcionado mostra uma menor concentração na diagonal em relação ao crédito livre (tabela 3). Observamos que 70,1\% das operaçóes classificadas como AA e $64,1 \%$ das operaçóes A mantiveram sua classificação original. Somente 59,9\% das operaçôes iniciadas com B mantiveram seu rating original, enquanto 27\% (somando 11,2\% com 15,8\%) apresentaram upgrade e aproximadamente 13,1\% apresentam downgrade na classificação de risco. As probabilidades de transição para as linhas de crédito direcionado confirmam que as instituiçôes operadoras dessas linhas experimentam vários episódios de inadimplência ao longo dos contratos de crédito.

TABELA 3

Matriz de transição de risco de crédito direcionado

(Em \%)

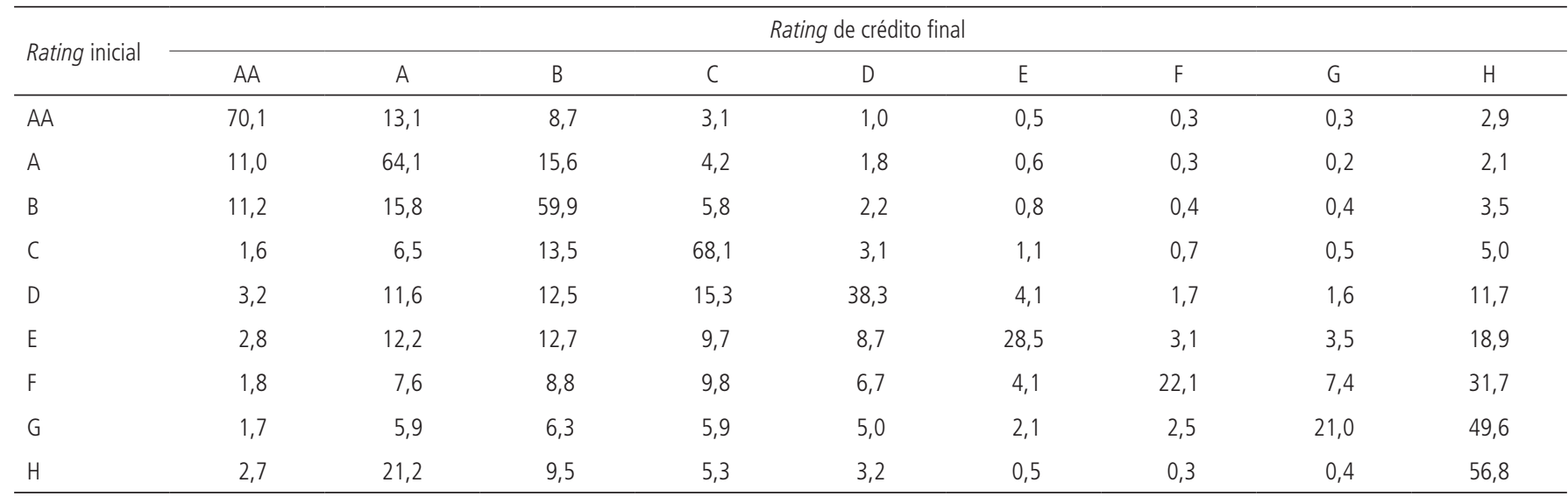

Fonte: SCR.

Elaboração dos autores.

Obs.: As linhas somam 100\%, e as probabilidades de piora nos ratings são obtidas pela diferença entre a diagonal e as linhas da matriz triangular superior. 
Os eventos de inadimplência ocorrem mesmo quando a instituição financeira é capaz de recuperar todo o valor desembolsado da operaçáo de crédito, seja por meio de renegociação ou cobrança judicial (Nazeran e Dwyer, 2015). Segundo o BCB, basta ocorrerem atrasos superiores a noventa dias para que haja caracterização de inadimplência. Sendo esta reconhecida, a instituição financeira deve efetuar as devidas mudanças nas provisóes previstas inicialmente, o que afeta a oferta de crédito destas instituiçôes. Uma vez que um contrato de crédito apresentou piora de rating, nem mesmo uma renegociação pode reverter a necessidade adicional de provisão de capital (tabela 1). ${ }^{4}$ Isto porque um contrato de crédito inadimplente, mesmo quando renegociado, carregará consigo a classificação do antigo contrato de crédito. Portanto, o apelo à renegociação não altera os requisitos mínimos de capital das instituiçóes financeiras. Por este motivo, renegociaçóes e inadimplência são tratadas de forma semelhante em modelos de risco de crédito em algumas instituiçóes financeiras (Moraux e Silaghi, 2014). Nesse sentido, são frágeis as argumentaçóes de que as operaçóes de créditos direcionados no mercado brasileiro possuem baixa inadimplência somente porque se lançou mão de mecanismos de renegociação. ${ }^{5}$

Para as linhas de crédito com recursos direcionados, vemos que as operaçôes especulativas, ou seja, abaixo de $\mathrm{D}$, possuem uma concentração de transiçóes para a categoria $\mathrm{H}$. Entre as operaçóes iniciadas com classificação $\mathrm{D}$, $11,7 \%$ degradaram para $\mathrm{H}$; no caso das operações iniciadas com classificação E, este valor foi de 18,9\%; já no caso das iniciadas com classificação F, foram 31,7\% as operaçóes degradadas. Houve alguns casos de melhorias para as categorias A e AA: 14,8\% (somando 3,2\% com 11,6\%) das operaçóes iniciadas com classificação D, $15 \%$ (somando 2,8\% com 12,2\%) das operaçóes E e 9,4\% (somando 1,8\% com 7,6\%) das operaçóes $\mathrm{F}$ tiveram upgrade para as classificaçóes A e AA.

De forma geral, as probabilidades de transição mostram que as operaçôes de crédito direcionado apresentam mais transiçóes de melhoria (upgrade) que as de crédito livre. As probabilidades de pioras de rating (downgrade), por seu turno, são iguais em ambos os casos. Os resultados podem indicar que, de alguma forma, o acesso ao crédito direcionado pode ter contribuído para a melhoria financeira das empresas, ainda que este não seja o objetivo típico deste tipo de financiamento. Em contrapartida, como as operaçóes de crédito livre são alocadas proporcionalmente para operaçóes com melhores classificações e com baixa probabilidade de transição, sobra menos espaço para upgrade nesse tipo de operação.

\section{CONCLUSÃO}

Apresentamos aqui as matrizes de transiçôes de risco de crédito para firmas brasileiras, comparando as linhas de créditos operados com recursos livres e direcionados. Mostramos que as operaçôes de crédito direcionado possuem maiores probabilidades de transição na direção de melhoras nos ratings. Por sua vez, os recursos livres são alocados para operaçôes com melhores classificações iniciais, sendo que no decorrer do ciclo de vida dessas operações ocorrem transições em relação à atribuição de rating inicial.

$\mathrm{Na}$ atribuição do nível de risco em contratos de crédito, não é desejável atribuir um nível nem superior, nem inferior ao necessário. Uma atribuição de risco desnecessariamente conservadora ocasionará o congelamento de recursos que poderiam ser utilizados em novos contratos, enquanto uma atribuição de nível de risco exageradamente otimista levará a ajustes inesperados ao longo do ciclo de vida do contrato. Considerando que divergências em

4. Ver Resolução no 4.660/2018 do BCB. Disponível em: <https://www.bcb.gov.br/pre/normativos/busca/downloadNormativo.asp?arquivo=/Lists/Normativos/ Attachments/50595/Res_4660_v1_0.pdf>.

5. Mais informações disponíveis em: <https://agenciadenoticias.bndes.gov.br/detalhe/fatoboato/Fato-A-taxa-de-inadimplencia-do-BNDES-e-inferior-a-doSistema-Financeiro-Nacional/>. 
relação à classificação original são indesejadas, seja na direção de downgrade ou de upgrade, os resultados encontrados indicam que os modelos de atribuição de risco utilizados em linhas de crédito direcionado podem ser mais frágeis que aqueles utilizados pelas instituiçóes privadas. Em contrapartida, as transiçóes em direção à melhoria de rating podem indicar que, de alguma forma, o acesso ao crédito pode ter contribuído para a recuperação financeira das empresas.

\section{REFERÊNCIAS}

HULL, J. C. The credit crunch of 2007: what went wrong? Why? What lessons can be learned? In: EVANOFF, D. D.; HARTMANN, P.; KAUFMAN, G. G. The first credit market turmoil of the 21st century. [s.l.]: [s.n.], 2009. p. 161-174.

JONES, M. T. Estimating Markov transition matrices using proportions data: an application to credit risk. Washington: IMF, 2005. (Working Paper, n. 05/219).

KOOPMAN, S. J.; LUCAS, A.; MONTEIRO, A. The multi-state latent factor intensity model for credit rating transitions. Journal of Econometrics, v. 142, n. 1, p. 399-424, 2008.

MORAUX, F.; SILAGHI, F. Inside debt renegotiation: optimal debt reduction, timing, and the number of rounds. Journal of Corporate Finance, v. 27, p. 269-295, 2014.

NAZERAN, P.; DWYER, D. Credit risk modeling of public firms: EDF9. Moody's Analytics, 2015.

WANG, Y. et al. Credit transition model 2017 update: methodology and performance review. Moody's Analytics, 2017.

YANAKA, G. M.; HOLLAND, M. Basileia II e exigência de capital para risco de crédito dos bancos no Brasil. Revista Brasileira de Finanças, v. 8, n. 2, p. 167-195, 2010. 
